\title{
Estenose Ureteropélvico Fetal - Diagnosticada pela Ultra-sonografia
}

\section{Fetal Uretero-Pelvic Stenosis - Diagnosed by Ultrasonography}

\author{
Guilherme de Almeida Bastos ${ }^{1}$ \\ Danilo Micheletto. Laurino ${ }^{2}$ \\ Marcelo Kazuo Kashiwabuch ${ }^{2}$ \\ Pedro Adri Oliveira Agostini ${ }^{2}$ \\ Rafael de Souza Ramos Ploch ${ }^{2}$
}

\section{Palavras-chaves: \\ Resumo}

Ultra-sonografia

Estenose

Ureteropélvico

Recém-nascido

Abstract

The authors report a case of stenosis in Uretero-Pelvic Junction at the left side, diagnosed in pre-birth by ultrasonography at the 28th week of gestation. The importance of the previous diagnosis was the interruption of gestation before the occurrence of a fetal renal loss or a irreversible renal lesion in neonate.

\section{Introdução}

As anomalias congênitas do trato urinário são responsáveis por grande parte das alterações que levam à insuficiência crônica e falência renal na infância. A alteração fetal mais frequentemente detectada no diagnóstico pré-natal é a hidronefrose, e apenas uma pequena parcela está associada a alterações urológicas significativas, as quais geralmente decorrem das uropatias obstrutivas altas, como a estenose das junções uretero-pélvica.

Nas últimas décadas, com o desenvolvimento da ultra-sonografia e suas indicações freqüentes durante a gravidez, aumentaram os diagnósticos precoces das malformações do trato urinário, possibilitando uma melhora prognóstica devido ao tratamento intra-uterino ou neonatal imediato.

A estenose da junção uretero-pélvica é a causa mais comum de hidronefrose no rim fetal, acometendo mais o sexo masculino
Key words:

Ultrasonography

Uretero-Pelvic

Stenosis

Neonate e o rim esquerdo, com graus diferentes de severidade. O diagnóstico é confirmado pela ultra-sonografia quando visualizamos a pelve renal dilatada e a ectasia dos ductos. Os ureteres, em geral, não são visíveis, a bexiga fetal é normal e a quantidade de líquido amniótico não se altera, principalmente quando o rim contralateral é normal. Caso tenhamos a presença de oligodrâmnio, isso acarreta um mau prognóstico, pois sugere a presença de agenesia ou displasia no rim contralateral. Os principais fatores relacionados ao prognóstico são a lateralidade do acometimento (uni ou bilateral), a ocorrência de oligodrâmnio, sendo que a condição causadora do óbito neonatal são as malformações extra-renais como a hipoplasia pulmonar.

Em relação ao tratamento, existem duas correntes terapêuticas: na hidronefrose leve a moderada, com padrão não obstrutivo

${ }^{1}$ Mestre - Fisioterapia - UniFOA

${ }^{2}$ Fisioterapeutas 
e função renal preservada, adotou-se uma conduta expectante com controles necessários de ultra-som na gravidez e ultra-som, urografia excretora e cintilografia no pósnatal; verificou-se, então, uma involução progressiva da dilatação, não requerendo tratamento cirúrgico, apenas acompanhamento clínico e laboratorial. Na hidronefrose grave há necessidade de correção cirúrgica pós-natal (ureteropielostomia e pelvectomia) para alívio da obstrução e preservação da função renal.

\section{Relato de caso}

Paciente T. S., 27 anos, leucoderma, primigesta, iniciou acompanhamento pré-natal no dia 08/08/06 na Policlínica da Mulher, na cidade de Volta Redonda-RJ. Com Pré-Natal de Alto Risco (PNAR), foram pedidos os exames de primeira rotina (DUM-05/06/06) o qual não apresentou nenhuma irregularidade. No PNAR foi feito um acompanhamento clínico e de exames ultrasonográfico mensal e no dia 27/11/06 foi diagnosticado, pela ultra-sonografia, uma imagem compatível com cisto renal à esquerda. No dia 20/12/06, a paciente fez outro exame de ultra-sonografia morfológica e 3D, que identificou uma "imagem sugestiva de dilatação da pelve renal esquerda fetal que media 27 x $21 \mathrm{~mm}$ de diâmetro" e nenhuma outras anormalidades anatômicas.

O acompanhamento clínico foi mantido até a ultra-sonografia do dia 22/02/07, quando tinha 37 semanas e 2 dias de amenorréia, observando-se: " uma acentuada dilatação do sistema pielocalicial renal esquerdo fetal. Nota-se também grande imagem cística regular, alongada, medindo 64 x $48 \mathrm{~mm}$ de diâmetro que pode corresponder a grande dilatação do ureter esquerdo fetal (estenose de junção ureteropélvico esquerda)", sem oligohidramnia, ILA $13 \mathrm{~cm}$, neste ínterim, a gestante desencadeou a doença hipertensiva específica da gravidez (DHEG). Nesta ocasião, a paciente foi encaminhada para a maternidade do Hospital Municipal São João Batista, para interrupção da gestação e avaliação do RN pela cirurgia pediátrica.

Entretanto, a cesariana foi realizada no dia 26/02/07 no Hospital Municipal São João Batista, após feitura do exame de ultrasonografia e Doppler velocimetria, para uma reavalição obstétrica antes do ato cirúrgico do binômio materno fetal. O recémnascido pesou 3885 gramas, capurro 37 semanas e 6 dias, Apgar 9/10, e foi internado no UTI neonatal no dia 27/02/07 a espera de cirurgia, no dia 03/03/07. A cirurgia do $\mathrm{RN}$ consistiu em uma ureteropielostomia + pelvectomia à esquerda, com tratamento peroperatório com Cefazolina do dia 03/03/07 a 06/03/07, Cefalexina do dia 07/03/07 a 20/03/07 e Gentamicina do dia 17/03/07 a 27/03/07, após colheita da urina para exames. No dia 18/03/07, o resultado da urocultura deu positivo para Enterobacter aeruginosos e sensíveis aos antibióticos usados.

No dia 14/03/07, foi realizado um estudo radiológico contrastado que demonstrou a passagem de contraste pela junção. A alta hospitalar curada do RN ocorreu após 24 dias da internação na UTI neonatal.

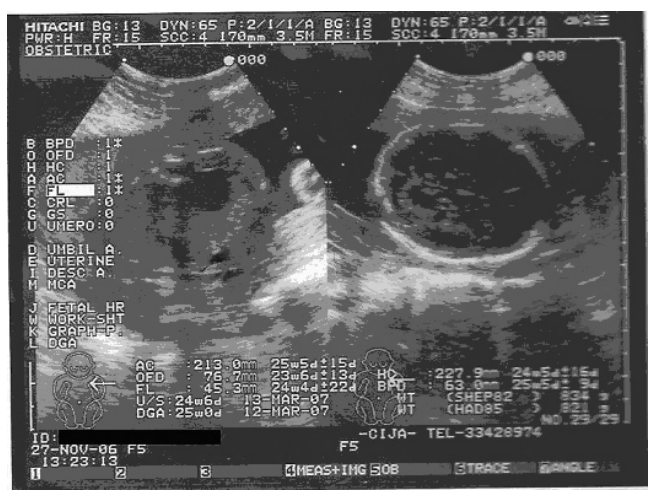

Fig 1- Presença de imagem anecóica em loja renal esquerda

\section{Discussão}

A obstrução da junção ureteropélvica é a causa mais freqüente de hidronefrose fetal (85-90\%). Sendo que a maior ocorrência se dá nos fetos de sexo masculino, e de forma unilateral em 70\% dos casos. (PASTORE E CERRI, 1997). A junçao ureteropélvica é sítio mais comum de obstrução do trato urinário, ocorrendo em um a cada 1.500 nascidos vivos. (APOCALYPSE, 2003)

Caso a obstrução não ocorra de uma forma total, podemos ter um desenvolvimento renal normal, se ela ocorrer durante o segundo trimestre da gravidez, poderemos observar uma hidronefrose, dependendo então o dano renal do grau e da duração da obstrução. Porém, quando a obstrução é completa e ocorre na fase precoce da vida intra-uterina, podemos observar no feto a ocorrência 
de hipoplasia renal (rins pequenos com parênquima renal aparentemente normal) e Potter tipo II (formação anormal de néfrons e estroma mesenquimal). (PILU, 2001)

O diagnóstico é dado por meio da ultra-sonografia, quando visualizamos uma pelve renal dilatada e ectasia dos ductos. Os ureteres, em geral, não são visíveis, a bexiga fetal é normal e a quantidade de líquido amniótico não se altera, principalmente, quando o rim contralateral é normal, caso tenhamos a presença de oligodrâmnio, isso acarreta um mau prognóstico, pois sugere a presença de agenesia ou displasia no rim contralateral. Algumas vezes, identificamos anomalias do trato urinário em $27 \%$ dos casos, como: refluxo vesicoureteral, duplicação ureteral bilateral, obstrução ureteral mais baixa, agenesia renal contralateral, estenose meatal e hipospádia. Anomalias do sistema extra-urinário podem ser vistas em 19\% dos casos ( PASTORE E CERRI, 1997)

A obstrução do ureter quase sempre não é completa e resulta de um estreitamento fibrótico intrínseco da junção entre o ureter e a pelve. Essa obstrução pode variar desde uma obstrução completa, rara, levando a alterações displásicas graves do parênquima renal, até a quadros de hidronefrose leve, nãoobstrutiva, que melhoram ao longo do tempo espontaneamente.

O dano renal inicial é menor nos casos detectados no período pré-natal, todavia, é controverso se há melhor resposta pós pieloplastia, quando comparado com crianças diagnosticadas tardiamente. Essa detecção precoce criou duas correntes terapêuticas: uma que defende a correção cirúrgica precoce, outra que opta pela observação criteriosa, reservando a cirurgia para os casos de deterioração renal. Desde então, muitos estudos têm avaliado se a conduta conservadora, não cirúrgica, é segura no manejo da obstrução da junção ureteropélvica, nesses casos, assintomática. $\mathrm{O}$ estudo de Ransley et al demonstrou que apenas $30 \%$ das unidades renais tratadas conservadoramente tiveram de ser submetidos à pieloplastia, uma vez que houve declínio da função renal na segunda avaliação cintilográfica. Outro estudo publicado recentemente foi realizado com o objetivo de avaliar a melhor abordagem da obstrução da junção ureteropélvica em recém-nascidos com hidronefrose de grau III e função renal diferencial maior que $40 \%$ no renograma. Após um ano de seguimento, o grupo submetido ao tratamento cirúrgico apresentou melhora significativa da hidronefrose e do padrão da cintilografia em comparação com o grupo de tratamento conservador. Contudo, não houve diferença significativa na comparação da função renal em ambos os grupos (OLIVEIRA, 2001).

Para os casos de hidronefrose grave (grau IV) - padrão obstrutivo inequívoco no renograma e função renal alterada - a indicação de correção cirúrgica é consensual entre os autores. No entanto, em casos de hidronefrose leve (grau I ou no máximo grau IV) - padrão não obstrutivo na cintilografia e com função renal preservada- a conduta conservadora é segura. Contudo, nos casos de hidronefrose moderada (grau II a IV), mas com padrão intermediário na cintilografia e função renal normal, a conduta ainda é controversa( FILHO, 2002)

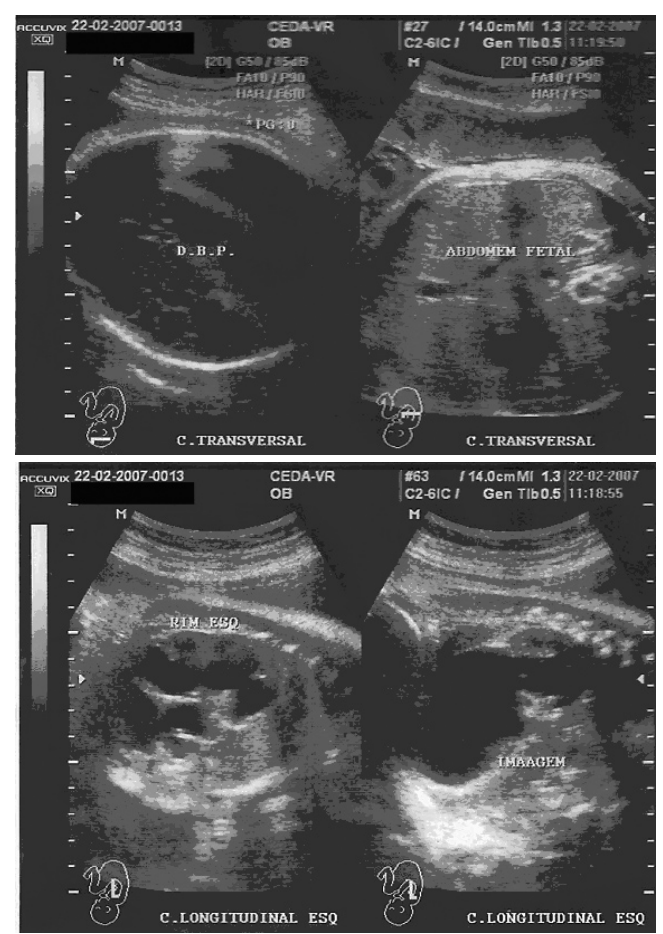

Fig 2 - Dilatação na junção ureteropélvica renal esquerda e hidronefrose de grau II

\section{Conclusão}

Nos dias atuais, a medicina fetal tem beneficiado os recém-natos, principalmente com o uso da ultrasonografia, favorecendo o diagnóstico precoce e intra-útero de patologias congênitas, propriciando o tratamento cirúrgico do RN no pós-parto imediato, evitando com isso lesões irreversíveis de órgãos vitais, em 
alguns casos e, em determinadas patologias, esse tratamento poderá ser realizado, também,

intra-útero.

\section{Referências}

APOCALYPSE, G. T., RABELO, E. A. S., DINIZ, J. S. S., MARINO, V. S. P., SIMAL, C. J. R., RODRIGUES, A. M., FAGUNDES L. A. e OLIVEIRA E. A. Abordagem da obstrução de junção ureterepélvica identificada na investigação de hidronefrose fetal. Rev Med Minas Gerais 2003; 13(4): 285-9

FILHO, A. A. M., MIRANDA, M.L., NETO, L. S., KÖHLER, H. F., SILVA, J. M. B. e BARINI, R. Hidronefrose pré-natal: Experiência do grupo de medicina fetal - UNICAMP. HB Científica, Janeiro - Abril 2002, Vol. 9 no 1 (11-18)

OLIVEIRA, E.A., DINIZ, J. S. S., MESQUITA, F.M. Revisão: Hidronefrose fetal - abordagem pós-natal, avanços e controvérsias. J Bras Nefrol 2001;23(3):15265

PASTORE, A. R., CERRI, G.C. Ultrasonografia: obstetrícia, ginecologia. editora Sarvier. 1997

PILU, G., NICOLAIDES, K., XIMESNES, R., JEANTY, P. Diagnóstico de Anomalias Fetais. The Fetal Medicine Foundation. 2001

VUOLO, M. E. L. Diagnóstico diferencial en ecografia obstétrica, 1992

Informações bibliográficas:

Conforme a NBR 6023:2002 da Associação Brasileira de Normas Técnicas (ABNT), este texto científico publicado em periódico eletrônico deve ser citado da seguinte forma:

BASTOS, G.A.;LAURINO, M.; KASHIWABUCH,M.K.;AGOSTINI,P.A.R.; RAMOS, R. S.. Estenose Ureteropélvico Fetal - Diagnosticada pela Ultra-sonografia. Cadernos UniFOA, Volta Redonda, ano 2, no. 5, dez. 2007. Disponível em: <http://www.unifoa.edu.br/pesquisa/caderno/edicao/05/80.pdf> 